\title{
ESTUDO DA EVAPORAÇÃO SOLAR DA SALMOURA NO PROCESSO DE CONCENTRAÇÃO DO LÍTIO DO SALAR DE UYUNI-BOLÍVIA
}

\author{
A. A. S. MENDOZA ${ }^{1}$, J. L. Z. ESCALANTE ${ }^{2}$, C. F. M. MOREJON ${ }^{1}$, A. C. ARAYA ${ }^{2}$ \\ ${ }^{1}$ Universidade Estadual do Oeste de Paraná - UNIOESTE, Programa de Pós- \\ Graduação de Engenharia Química \\ ${ }^{2}$ Facultad Nacional de Ingeniería/Universidad Técnica de Oruro - FNI/UTO \\ *e-mail: camilo_freddy@hotmail.com
}

\section{RESUMO}

$\mathrm{Na}$ América do Sul se encontra o maior deserto de sal do mundo (salar de Uyuni-Bolívia com $10.000 \mathrm{~km}^{2}$ de superfície), metade da reserva mundial do lítio está disponível para diversas aplicações. Na atualidade o Lítio é obtido na forma de Carbonato, cuja etapa preliminar, visando o aumento da concentração do lítio na salmoura (Solução composta de $\mathrm{Li}, \mathrm{K}, \mathrm{Na}, \mathrm{SO}_{4}, \mathrm{Cl}$, e $\mathrm{Mg}$ ), utiliza processos de separação por evaporação solar a céu aberto. No presente trabalho se apresenta resultados da influência das variáveis operacionais no fluxo de evaporação da salmoura do salar de Uyuni-Bolívia. A metodologia contemplou: a) o projeto/construção do módulo experimental; b) o monitoramento transiente do fluxo de evaporação, temperatura ambiente, umidade relativa e radiação solar; e c) o estudo da composição química dos elementos presentes na salmoura em função da porcentagem de evaporação. Para as condições reais de operação o fluxo de evaporação da salmoura, numa superfície de contato de convecção natural de $0,018 \mathrm{~m}^{2}$, foi de $0,63 \mathrm{~kg}_{\text {água }} \mathrm{m}^{-2} \mathrm{~h}^{-1}$. A evaporação global correspondeu a $51 \%$ da salmoura original, no qual a umidade relativa teve uma maior influência quando comparado com a temperatura ambiente e a radiação solar.

\section{INTRODUÇÃO}

Segundo EVANS (2008) e United States Geological Survey (2011), conforme Tabela 1, as principais reservas de Lítio na América do Sul são encontrados num local subterrâneo de 30 a $50 \mathrm{~m}$ de profundidade e em estado líquido nos desertos de sal da Bolívia, Chile e Argentina.

Segundo COCHILCO (2009), a concentração de lítio na Salmoura da Argentina, Bolívia e Chile, variam num intervalo de 350 a $1500 \mathrm{mg} / \mathrm{l}$. Na Tabela 2 se apresenta a concentração média dessas salmouras.

Tabela 1 - Reservas de Lítio na América do Sul.

\begin{tabular}{llr}
\hline \multicolumn{1}{c}{ Pais } & \multicolumn{1}{c}{ Local } & \multicolumn{1}{c}{ T de Li } \\
\hline Bolívia & Salar de Uyuni & 9.500 .000 \\
Chile & Salar de Atacama & 6.900 .000 \\
& Salar do Homem & \\
Argentina & Morto & 850.000 \\
\hline
\end{tabular}

Fonte: Evans (2008) e United States Geological Survey (2011). 
Tabela 2 - Concentração de Lítio na Salmoura.

Pais Local Concentração

de Lítio mg/l

\begin{tabular}{llr}
\hline Chile & Salar de Atacama & 1500 \\
Argentina & Salar do Homem Morto & 692 \\
Bolívia & Salar de Uyuni & 350 \\
\hline
\end{tabular}

Fonte: COCHILCO (2009).

\subsection{Composição Química da Salmoura}

Segundo RODRIGUEZ (1994), em geral a salmoura é composta de $\mathrm{Li}, \mathrm{Na}, \mathrm{K}$, $\mathrm{Mg}, \mathrm{SO}_{4}$ e $\mathrm{Cl}$. Na Tabela 3 se apresenta a composição da salmoura na América do Sul (MILLAS, 2000).

Tabela 3 - Composição da Salmoura na América do Sul medida em porcentagem em peso.

\begin{tabular}{lcccccc}
\hline $\begin{array}{l}\text { Salmouras } \\
\text { de lítio }\end{array}$ & $\mathrm{Li}$ & $\mathrm{Na}$ & $\mathrm{K}$ & $\mathrm{Mg}$ & $\mathrm{SO} 4$ & $\mathrm{Cl}$ \\
\hline $\begin{array}{l}\text { Bolívia: } \\
\text { Salar de }\end{array}$ & & & & & & \\
$\begin{array}{l}\text { Uyuni } \\
\text { Chile: }\end{array}$ & 0,025 & 8,8 & 0,7 & 0,65 & 0,046 & 15,7 \\
$\begin{array}{l}\text { Salar de } \\
\text { Atacama }\end{array}$ & 0,14 & 7,6 & 1,9 & 0,93 & 0,03 & 16 \\
$\begin{array}{l}\text { EEUU. } \\
\text { Great Salt }\end{array}$ & & & & & & \\
Lake, Utah & 0,004 & 8 & 0,7 & 1 & 0,016 & 14 \\
\hline
\end{tabular}

Fonte: Millas (2000)

\subsection{Evaporação Solar das Salmouras}

Segundo GARZÓN (1999) nos processos de evaporação solar de salmouras, devido a separação da água, acontece o aumento da concentração do lítio e simultaneamente a cristalização do cloreto de sódio $(\mathrm{NaCl})$ e do cloreto de potássio $(\mathrm{KCl})$. Segundo CONDORETTI (2010), a cristalização do cloreto de sódio e do cloreto de potássio influencia na eficiência de recuperação do Lítio.

No presente trabalho estudaram-se: a) o fluxo de evaporação solar da água presente na salmoura; b) a influência da umidade relativa, temperatura ambiente, e da radiação solar na eficiência da evaporação; e c) o estudo da composição química da salmoura em função da porcentagem de evaporação.

\section{MATERIAIS E MÉTODOS}

A metodologia de estudo contemplou a realização de 3 etapas: 1) Projeto/Construção do módulo experimental; 2) Monitoramento transiente das variáveis e parâmetros operacionais, entre eles: o fluxo de evaporação da água $\left(\mathrm{kg}_{\text {água }} \mathrm{m}^{-2} \mathrm{~h}^{-1}\right), \quad$ a temperatura ambiente $\left({ }^{\circ} \mathrm{C}\right)$, a umidade relativa (\%), a radiação solar (Langley) e a composição química dos elementos presentes na salmoura em função do porcentagem de evaporação; e 3) Análise e consolidação dos resultados.

\subsection{Etapa 1 - Projeto/Construção do módulo experimental}

O projeto construção do módulo experimental contemplou o estudo do arranjo experimental, características geométricas dos elementos constitutivos e escolha dos materiais apropriados. De modo geral o módulo experimental possui um recipiente para conter a salmoura, uma carcaça transparente, multifuncional, para avaliar a influencia da radiação e da convecção, bem como dos instrumentos de medição. Para a construção do recipiente que contém a salmoura, foi utilizado chapas de ferro galvanizado revestidos com pintura anticorrosiva. A geometria escolhida foi o volume retangular de $540 \mathrm{ml}$, com superfície constante de $0,018 \mathrm{~m}^{2}$ e altura de $0,03 \mathrm{~m}$.

\subsection{Etapa 2 - Monitoramento das Variáveis e Parâmetros Operacionais}

Para realizar o monitoramento em regime transiente do fluxo de evaporação da água $\left(\mathrm{kg}_{\text {água }} \mathrm{m}^{-2} \mathrm{~h}^{-1}\right)$, da temperatura ambiente $\left({ }^{\circ} \mathrm{C}\right)$, da umidade relativa $(\%)$, da radiação solar (Langley), e a determinação química dos elementos presentes na salmoura, foram utilizados: uma balança com uma precisão de duas caixas decimais, um termômetro eletrônico, um higrômetro, um medidor de radiação solar, um cronômetro, e 


\section{ENEMP \\ Terr \\ São Carlos - SP}

metodologias de análise química. $\mathrm{O}$ monitoramento de cada uma das variáveis foi registrado de hora em hora entre $8 \mathrm{~h} 00$ e $18 \mathrm{~h} 00$.

\subsection{Etapa 3 - Análise e Consolidação de Resultados}

A análise e a consolidação dos resultados foi realizado com ajuda de planilhas eletrônicas e os resultados foram apresentados por meio de gráficos.

\section{RESULTADOS}

\subsection{Resultados da Etapa 1 - Projeto/Construção do módulo experimental}

O resultado do projeto e construção do módulo experimental se apresenta na Figura 1. O módulo experimental contemplou um recipiente retangular, provido de balança para monitorar a diminuição do peso da salmoura, carcaça de vidro e dispositivos de medição.

Figura 1 - Projeto do Modulo Experimental.

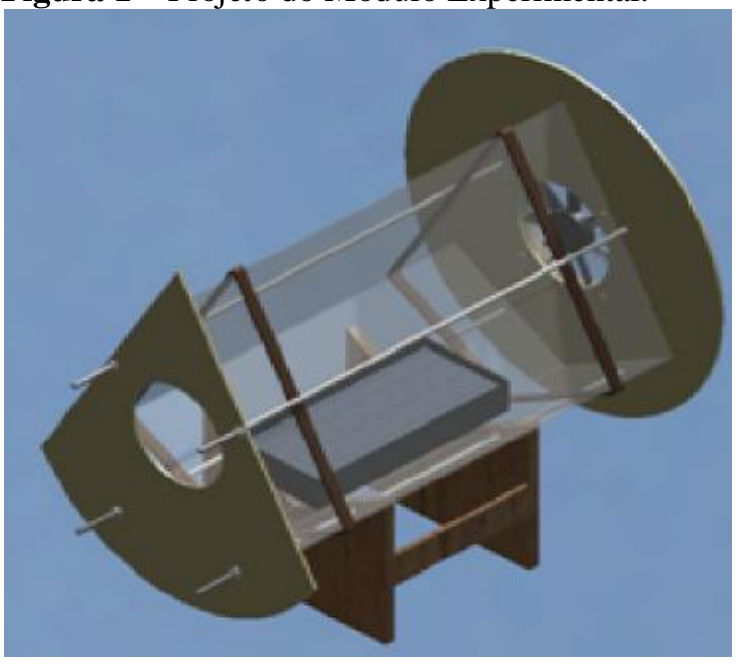

Na Figura 2 se apresenta o resultado do efeito corrosivo da salmoura o que justificou a necessidade da aplicação de revestimento a base de laca e nitrocelulose, cujo resultado se mostra na Figura 3.
Figura 2 - Corrosão no Recipiente.

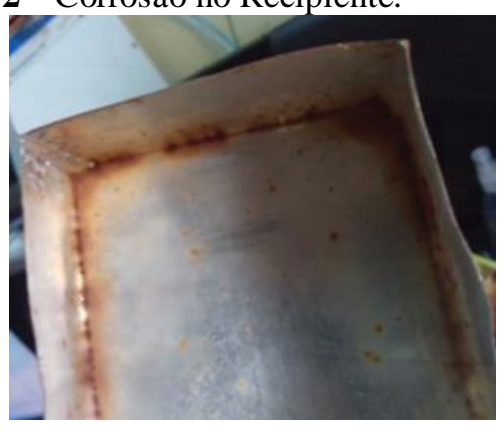

Figura 3 - Recipiente revestido com uma Pintura a Base de Laca e Nitrocelulose.

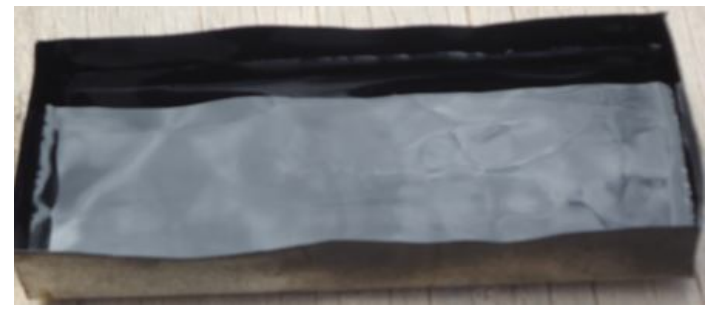

Após aplicação do revestimento os testes experimentais ocorridos durante 10 dias mostrou que o revestimento utilizado inibe a corrosão da chapa de ferro e facilita também a retirada dos cristais, os quais não tiveram aderência na superfície do recipiente.

\subsection{Resultados da Etapa 2 - Monitoramento das Variáveis e Parâmetros Operacionais}

$\mathrm{O}$ monitoramento das variáveis e parâmetros operacionais foi realizado no mês de fevereiro. Os experimentos e o monitoramento das variáveis foram realizadas na Faculdade Nacional de Engenharia da Universidade Técnica de Oruro localizada na cidade de Oruro-Bolívia, onde a pressão atmosférica é de $476 \mathrm{mmHg}$ e se encontra a 3.735 metros sobre o nível do mar. Para o estudo foi utilizado salmoura proveniente do Salar de Uyuni-Bolívia. O resultado do processo de evaporação solar da salmoura e a formação de cristais no recipiente se mostra na Figura 4. Para o estudo do processo de evaporação foram considerados condições naturais de temperatura, umidade relativa e 


\section{ENEMP \\ 然 \\ São Carlos - SP}

presença de vento máximo, médio e mínimo reportados no mês de fevereiro.

Figura 4 - Resultado do processo de Evaporação Solar/cristalização da Salmoura.

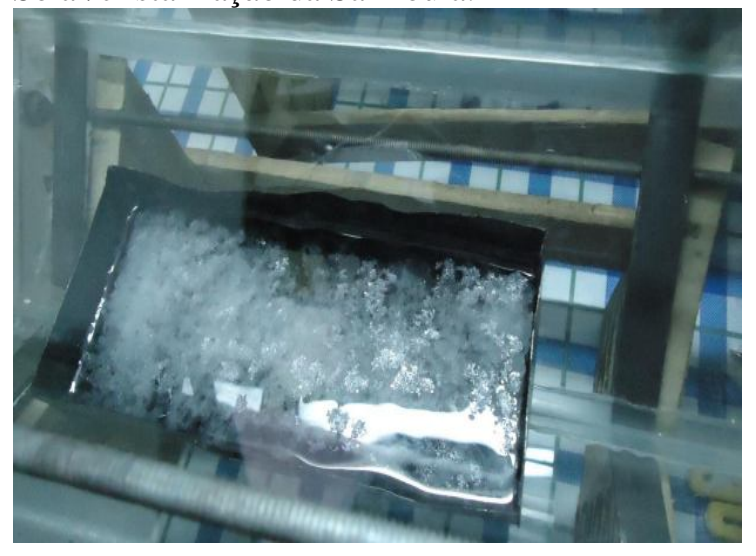

\subsection{Análise e Consolidação de Resultados}

Na Figura 5 se apresenta a variação da temperatura ambiente em função do tempo para os dias 13, 15 e 18 de fevereiro 2014. Com base do monitoramento foi constatado que: no dia 13 de fevereiro a temperatura média foi de $15^{\circ} \mathrm{C}$, tendo como mínimo $10,7^{\circ} \mathrm{C}$ e um máximo de $17,5^{\circ} \mathrm{C}$; no dia $15 \mathrm{de}$ fevereiro a temperatura média foi de $16,79^{\circ} \mathrm{C}$, tendo como mínimo $15,1^{\circ} \mathrm{C}$ e um máximo de $19,6^{\circ} \mathrm{C}$; e no dia 18 de fevereiro a temperatura média foi de $16,46^{\circ} \mathrm{C}$, tendo como mínimo $14,5^{\circ} \mathrm{C}$ e um máximo de $18,4^{\circ} \mathrm{C}$.

Figura 5 - Representação da Variação da Temperatura em função do Tempo nos dias 13,15 e 18 de Fevereiro de 2014.

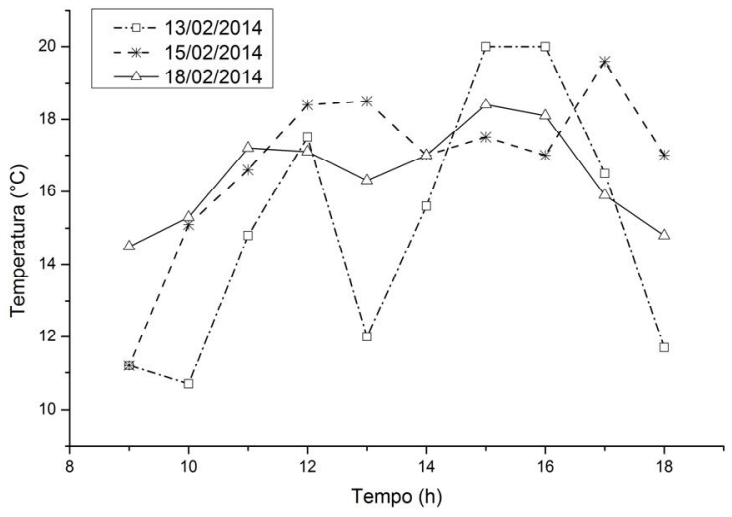

Na Figura 6 se apresenta a variação da umidade relativa em função do tempo para os dias 13, 15 e 18 de fevereiro de 2014. Com base do monitoramento foi constatado que: no dia 13 de fevereiro a umidade relativa média foi de $76 \%$, tendo como mínimo $65 \%$ e valor máximo de $86 \%$; no dia 15 de fevereiro a umidade relativa média foi de $64,1 \%$, tendo como mínimo $55 \%$ e valor máximo de $84 \%$; e no dia 18 de fevereiro a umidade relativa média foi de 52,2\%, tendo como mínimo $47 \%$ e valor máximo de $59 \%$. A umidade relativa maior do dia 13/02 foi devido às precipitações pluviais ocorridas nesse dia, o qual teve repercussão até o dia 15/02. Os resultados da umidade relativa do dia 18/02 correspondem ao dia ensolarado sem precipitação pluvial.

Figura 6 - Representação da Variação da Umidade Relativa em função do tempo nos dias 13, 15 e 18 de Fevereiro de 2014.

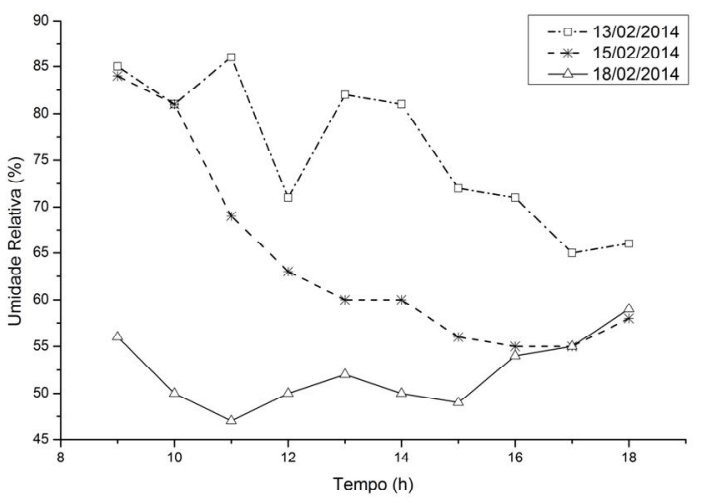

$\mathrm{Na}$ Figura 7 se apresenta a variação da temperatura do ambiente $\left({ }^{\circ} \mathrm{C}\right)$, umidade relativa (\%) e o porcentagem de evaporação (\%) em função do tempo, para o período diurno do dia 13 de fevereiro de 2014 (dia com precipitação, e com uma velocidade média do vento igual a $0,66 \mathrm{~m} / \mathrm{s}$ ). Com base no monitoramento foi constatado que a porcentagem global de evaporação, nesse período, atingiu $6,1 \%$ e o fluxo de evaporação alcançou $0,073 \mathrm{~kg}_{\text {água }} \mathrm{m}^{-2} \mathrm{~h}^{-1}$. 
Figura 7 - Representação da Variação Diurna da Temperatura Ambiente, Umidade Relativa e o Porcentagem da Evaporação em Função do Tempo no dia 13 de fevereiro de 2014

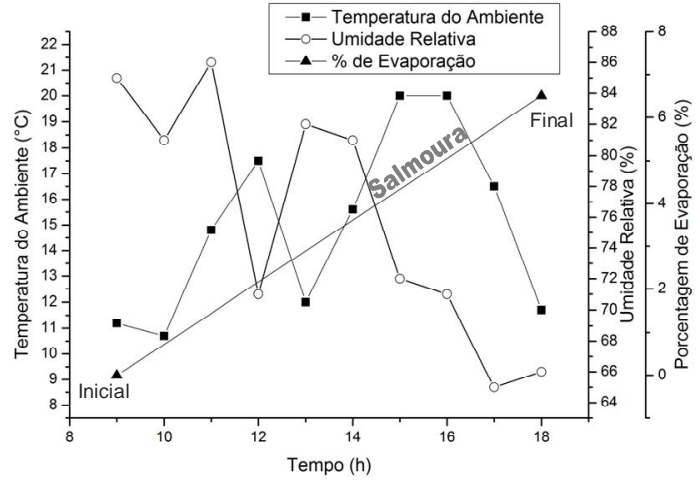

Na Figura 8 se apresenta a variação da temperatura do ambiente $\left({ }^{\circ} \mathrm{C}\right)$, umidade relativa $(\%)$ e a porcentagem de evaporação (\%) em função do tempo, para o período diurno do dia 15 de fevereiro de 2014 (Dia ensolarado sem precipitação pluvial, e com uma velocidade média do vento igual a $2,08 \mathrm{~m} / \mathrm{s}$ ). Com base no monitoramento foi constatado que a porcentagem global de evaporação, nesse período, atingiu $45 \%$ e o fluxo de evaporação na salmoura alcançou $0,55 \mathrm{~kg}_{\text {água }} \mathrm{m}^{-2} \mathrm{~h}^{-1}$.

Figura 8 - Representação da Variação Diurna da Temperatura Ambiente, Umidade Relativa e o Porcentagem da Evaporação em Função do Tempo no dia 15 de fevereiro de 2014.

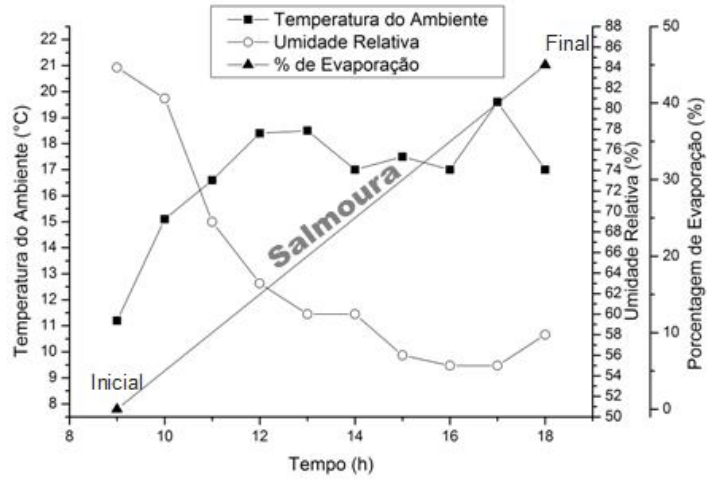

Na Figura 9 se apresenta a variação da temperatura do ambiente $\left({ }^{\circ} \mathrm{C}\right)$, umidade relativa (\%) e o porcentagem de evaporação (\%) em função do tempo, para o período diurno do dia 18 de fevereiro de 2014 (dia ensolarado sem precipitação pluvial, e com uma velocidade média do vento igual a $1,6 \mathrm{~m} / \mathrm{s})$. Com base no monitoramento foi constatado que a porcentagem global de evaporação, nesse período, atingiu $51 \%$ e o fluxo de evaporação alcanço $0,63 \mathrm{~kg}_{\text {água }} \mathrm{m}^{-2} \mathrm{~h}^{-1}$.

Figura 9 - Representação da Variação Diurna da Temperatura Ambiente, Umidade Relativa e o Porcentagem da Evaporação em Função do Tempo no dia 18 de fevereiro de 2014

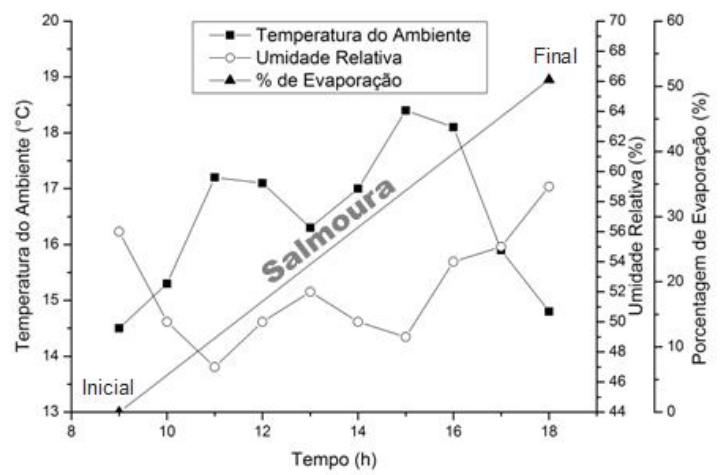

Conforme Figuras 7, 8 e 9 a maior porcentagem de evaporação encontrado no monitoramento foi do dia 18 de fevereiro, na qual a porcentagem global de evaporação atingiu $51 \%$ equivalente a um fluxo de evaporação de $0,63 \mathrm{~kg}_{\text {água }} \mathrm{m}^{-2} \mathrm{~h}^{-1}$. no período diurno, este resultado se atribui principalmente pela diminuição da umidade relativa do meio ambiente e o aumento da temperatura do ambiente.

Por meio da Figura 10, pode-se constatar que o comportamento químico dos elementos é altamente influenciado pela variação da porcentagem de evaporação num processo de convecção natural, podendo-se identificar o seguinte: A porcentagem em peso do sódio, na salmoura, diminui com o aumento da porcentagem de evaporação, este fenômeno acontece porque a solução fica num estado de 


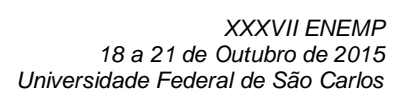

sobre-saturação produzindo dessa forma um produto sólido na forma de cristais cúbicos de cloreto de sódio $\mathrm{NaCl}$; a porcentagem em peso do cloro, na salmoura, aumenta proporcionalmente com o aumento da porcentagem de evaporação; para o caso da composição em peso do magnésio e do potássio foi constatado uma diminuição considerável no volume de evaporação igual a 10\%; e para o caso do lítio conseguiu-se verificar que a porcentagem em peso, desse elemento, aumenta proporcionalmente com o aumento da fluxo de evaporação.

Figura 10 - Representação Gráfica da Composição em Peso dos Elementos Presentes na Solução (Salmoura) em Função da Porcentagem de Evaporação.

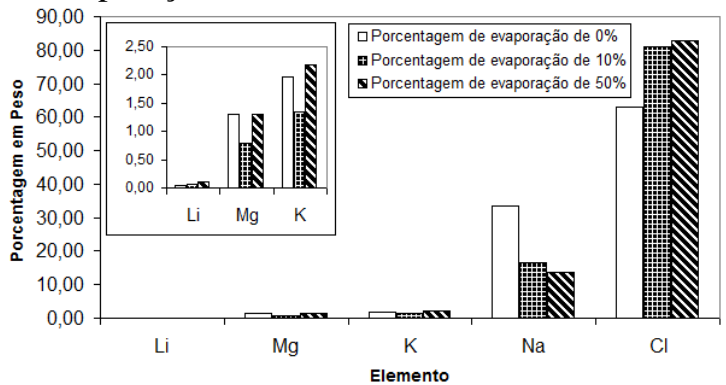

\section{CONCLUÇÃO}

Por meio dos resultados apresentados pode-se evidenciar que a fluxo de evaporação solar apresenta valores significativos quando a umidade relativa atinge a valores menores que $52 \%$, sendo que o fluxo de evaporação da salmoura, nessas condições ambientais, alcançou $0,63 \mathrm{~kg}$ água $^{-2} \mathrm{~m}^{-1}$.

Com base nos testes experimentais feitos na escala laboratorial do sistema de evaporação solar foi constatada que a radiação é inversamente proporcional a umidade relativa, e este último possui uma influência maior no fluxo de evaporação solar da salmoura do salar de Uyuni-Bolívia.

Com relação ao estudo da análise química pode-se concluir que o processo de evaporação solar afeta diretamente: no

aumento da concentração do lítio na solução concentrada; na separação do sódio (por meio da cristalização) e em pequenas quantidades também na formação de cristais de potássio e magnésio.

\section{REFERÊNCIAS}

COCHILCO. Antecedentes para una Política Pública en Minerales Estratégicos: Lítio. 2009. Disponível em: < http://ciperchile.cl/pdfs/litio/estudio_cochilco. PDF> Acesso em: 11 jun. 2015

CONDORETTI. Cinética de Cristalización del Cloruro de sodio. 2010, Universidad Técnica de Oruro, Oruro, Bolivia, 2010.

EVANS, R. K. An Abundance of Lithium. 2008. Disponível em: < http://www.che.ncsu.edu/ILEET/phevs/lithiu m-

availability/An_Abundance_of_Lithium.pdf> Acesso em: 11 jun. 2015

GRUBER P. W., Medina P. A., Keoleian G. A., et al. Global Lithium Availability. 2011. Disponivel em: < http://www.eenews.net/assets/2011/07/27/doc ument_gw_02.pdf> Acesso em: 11 jun. 2015

MILLAS I. J. La Indústria Del Litio en Chile. 2000. Disponível em: < http://www.uantof.cl/salares/Litio\%20y\%20deri vados.pdf > Acesso em 9 jun. 2015.

GARZÓN M. M. S. Estudio de la Velocidad de Evaporación y Cristalización. 1999. 118 p, Universidad Técnica de Oruro, Oruro, Bolivia, 1999.

RODRIGUES F. J. Z. Recuperación del KCl por Cristalización a Partir de Salmueras. 1994. 164 p, Universidad Técnica de Oruro, Oruro, Bolivia, 1994. 